\title{
Regulation must be revolutionized
}

\section{Unjustified and impractical legal requirements are stopping genetically engineered crops from saving millions from starvation and malnutrition, says Ingo Potrykus.}

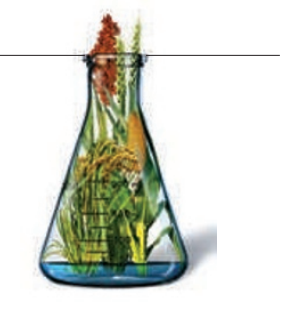

$\square$ enetically engineered crops could save many millions from starvation and malnutrition - if they can be freed from excessive regulation. That is the conclusion I've reached from my experience over the past 11 years chairing the Golden Rice Humanitarian project (www.goldenrice.org), and after a meeting at the Vatican last year on transgenic plants for food security in the context of development ${ }^{1}$.

Golden rice will probably reach the market in 2012 . It was ready in the lab by 1999 . This lag is because of the regulatory differentiation of genetic engineering from other, traditional methods of crop improvement. The discrimination is scientifically unjustified. It is wasting resources and stopping many potentially transformative crops such as golden rice making the leap from lab to plate.

More defensible - on scientific and humanitarian grounds - and more practical would be for new genetically modified crops to be regulated, not according to how they are bred, but according to their novelty, as are new drugs. All traits, however introduced, should be classified by their putative risk or benefit to the consumer and to the environment. Researchers and regulators could then focus on cases in which risks are real and fast-track crops urgently needed in the developing world.

Golden rice is a series of varieties modified with two genes (phytoene synthase and phytoene double-desaturase) to produce up to 35 micrograms of vitamin A precursor per gram of edible rice. Within the normal diet of ricedependent poor populations, it could provide sufficient vitamin A to reduce substantially the 6,000 deaths a day due to vitamin A deficiency, and to save the sight of several hundred thousand people per year ${ }^{1}$. None of the existing varieties of rice has even low levels of the vitamin A precursor in the part that is eaten, so conventional breeding cannot increase it. Golden rice was possible only with genetic engineering.

The crop was stalled for more than ten years by the working conditions and requirements demanded by regulations (see 'From bench to belly'). For example, we lost more than two years for the permission to test golden rice in the field and more than four years in collecting data for a regulatory dossier that would satisfy any national biosafety authority. I therefore hold the regulation of genetic engineering responsible for the death and blindness of thousands of children and young mothers.

Our experience is far from unique. It generally takes about ten times more money and ten years longer to bring a genetically modified crop to market than a non-genetically modified one. This keeps public research institutions out of the game and has given a handful of companies a de facto monopoly on the technology. Private ventures justifiably focus on the most profitable opportunities - industrial crops such as corn,

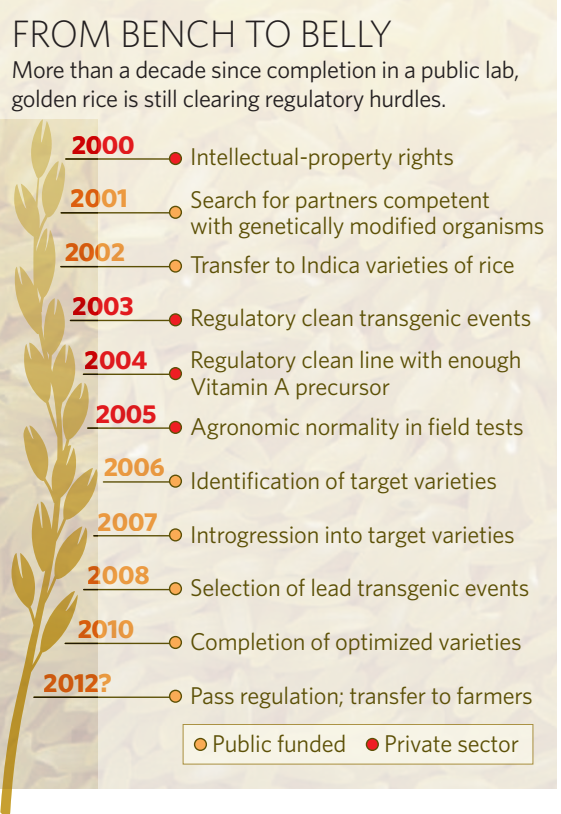

cotton and soya beans. Genetic engineering, however, has massive potential to also address food-security problems - to increase yield by protecting subsistence food crops from pests and diseases, to strengthen crops' competition with weeds and to improve plants' nutritional value.

\section{Running the gauntlet}

Existing regulation demands many years' worth of molecular and biochemical safety tests. Yet multiple international agencies have found genetic-engineering crop technology to be benign. There have not been any substantiated cases of harm to the environment or to humans, even in the litigious United States where the adoption of genetic engineering is widespread.

Meanwhile, a new plant created by traditional breeding methods - which also modify the genome - requires no safety data, only the demonstration that it performs at least as well as others. It is a quick and cheap process.
This imbalance allows non-scientific opponents of genetic engineering to raise unfounded concerns, which a nervous public cannot properly evaluate, especially in Europe.

All of this means that engineering varieties for the public good depends - ironically — on the private sector.

Golden rice is a prime example ${ }^{1}$. Only within the framework of a public-private partnership with Syngenta was our team able to navigate the product-development morass. Without Syngenta we could not, for example, have reduced the number of patents involved, secured free licences, established managerial and marketing structures or developed plants that are optimized to meet regulatory requirements and to express high levels of desired traits ${ }^{1}$.

Yet it is the responsibility of the public sector to address the crop needs of poor people. And it is wiser to spend public funds on feeding the world's growing population than on jumping through regulatory hoops, or worse on spurious, politically expedient research into hypothetical risks for the environment or the consumer, which have already been studied carefully over the past 25 years.

A good next step would be for a country with political and economic independence to recognize the arguments in favour of reducing the current regulatory burden for genetically engineered crops. Such a country would gain enormously by freeing funds, time and energy for research, development and deployment of many more genetically engineered crops for poor people; its public sector and small enterprises would be able to compete with the larger industries. Without compromising safety, that nation would easily progress faster than those continuing to focus on hypothetical risks, and it would provide some much needed leadership. Perhaps then, lab-ready varieties from the public domain such as golden cassava, golden banana, iron-, zinc- and protein-rich rice might get from bench to belly in 5 years, rather than 15 , if at all.

Ingo Potrykus is chairman of the Golden Rice Humanitarian Board. His address is address is Im Stigler 54, CH-4312 Magden, Switzerland. e-mail: ingo@potrykus.ch
1. Potrykus, I. \& Ammann, K. (eds) Transgenic Plants for Food Security in the Context of Development (New Biotechnology, in the press).

See Editorial, page 531, and food special at www.nature.com/food. 